\title{
The Effects of Large Volume Liposuction on Body Weight
}

\author{
ASMAA MOHAMMED ABD EL KHALEK ELMEHRAT, M.Sc.*; TAREK FOUAD KISHK, M.D.**; \\ AHMED F. ABDULLAH, M.D.** and AHMED ABDELAZIZ TAALAB, M.D.**
}

The Department of Plastic and Reconstructive Surgery, Berket El-Sabae General Hospital* and

Plastic and Reconstructive Surgery Department, Faculty of Medicine, Menoufia University**, Egypt

\begin{abstract}
Objective: To study the effect of large volume liposuction on body weight and total body fat in overweight and obese patients (BMI from 25-35) and in patients with localized lipodystrophy.

Background: Liposuction has become one of the most popular cosmetic procedures performed by plastic surgeon.

Method: This study was conducted on 31 patients presented with localized accumulation of fat either in thigh, abdomen, back or gluteal region and arms or in generalized overweight patients with BMI 25-30 and obese patients' class 1 with BMI 30-35 will undergo large volume liposuction in Plastic Surgery Department, Faculty of Medicine, Menoufia University. All studied patients were subjected to take a full history, general examination and local examination (for the area to be suctioned). Laboratory investigations as: Complete blood counts (CBC), blood glucose level, kidney function tests, liver function tests and bleeding profile.
\end{abstract}

Results: There were statistically significant difference between preoperative measurements of total body fat and (3 months, 6 months) postoperatively $(p<0.01)$.

There was statistically significant difference between the preoperative measurements of visceral fat and postoperative measurements (after 3 months and 6 months) $(p<0.01)$.

Conclusion: We found that the large volume liposuction in our patients, significantly reduces the weight, BMI, total body fat, visceral fat, circumference of abdomen and gluteal region.

Key Words: Body - Effects - Large volume - Liposuction Weight.

\section{INTRODUCTION}

Liposuction has become quite possibly the most corrective and cosmetic methods performed by plastic surgeon. Although, liposuction isn't an actually technically difficult operation but it still thoughtful arranging, planning and need an artistic eye to get aesthetically and stylishly postoperative satisfying outcomes [1].

Liposuction viewed as the most common surgical procedures for obesity in the world as re- moving excess fat stored in specific regions of the body for example two-foldchin, cheeks, neck and upper arms, the breast, abdomen, buttock, hips, lower appendages as thighs, calves and lower legs [2].

There are various techniques of liposuction like dry, wet, super wet and lastly tumescent techniques. Liposuction has developed in the last decades as introduction of tumescent and super wet techniques, ultrasonic liposuction, power-assisted liposuction and newly laser assisted liposuction [3].

Liposuction is successful in changing the contour, as it permanently eliminates fat cells which are inconsistently disseminated. The remaining adipocytes still store fat. So that, liposuction cannot prevent further more weight pick up, yet somewhat impact weight appropriation [4].

Liposuction should not be approached as the treatment for obesity; it is used for extraction of genetically disturbed or diet resistant fat [5].

The weight of the patients is more important determinant consideration for evaluation the extreme volume of fat to besecurely eliminated. Customarily, the volume of real fat in liters that eliminated securely in average patient should be 4-5\% of that patient's body weight in kilograms. Large volume liposuction was defined and characterized as more than $3.5 \mathrm{~L}$ of lipoaspirate [6].

Also, the current meanings of large volume liposuction are either total fat expulsion during operation (e.g., 4L of fat expulsion) orabsolute volume aspirated in the operation (fat in addition to wetting solution) (e.g., 5L of total volume removal). Large volume liposuction can be securely performed if rules are followed, careful selection of patients is critical important in large volume liposuction. Numerous overweight patients may 
be bad candidate for the large volume liposuction for the physiological mental and psychological reasons [7].

In obese patients, conservative surgery would be up to $6 \%$ of body weight as unharmed volume of complete aspirate. For grossly obese patients some would possibly consider more $6 \%$ of body weight. Incontinental Europe, more aggressive approach is taken and for grossly obese patients' removal of up to $10 \%$ of the body weight without any published complications [8].

We studied the effect of large volume liposuction on body weight and total body fat in overweight and obese patients (BMI from 25-35) and in patients with localized accumulation of fats in normal person.

\section{PATIENTS AND METHODS}

The study was affirmed by the ethical committeeof Faculty of Medicine, Menoufia University. This study was conducted on 31 patients presenting with localized obesity either in thigh, abdomen, back or gluteal region and arms or in generalized overweight patients with BMI 25-30 and obese patients' class 1 with BMI 30-35 will undergo large volume liposuction in Plastic Surgery Department, Faculty of Medicine, Menoufia University in the period from December 2017 to December 2019.

Inclusion criteria included: Sex: Male and female. Age: 20 years old to 50 years old. Medical history: No history of cardiac disease, renal disease and liver disease. Body weight: From $70 \mathrm{Kg}$ to $120 \mathrm{Kg}$. BMI: Range from 20 to 35. General condition: Good general condition and fit for surgery. Laboratory investigations: Within normal ranges.

Exclusion criteria included age: Less than 20 years old and above 50 years old. Body weight: Less than $70 \mathrm{Kg}$ and more than $120 \mathrm{Kg}$. MI: More than 35. General health: Poor general condition as cardiac disease and neurological diseases, pulmonary diseases, liver diseases and renal diseases. Patients with over expectations [Body dysmorphicsyndrome (BDS)].

All studied patients were subjected to the following: Full history to detect any medical disease as diabetes mellitus, hypertension and cardiac disease and special habit as smoking. General examination. Local examination: For the area to be suctioned and examination of the abdomen for the hernia in abdominal liposuction. Laboratory investigations as: Complete blood counts (CBC), kidney function tests, liver function tests, bleeding profile and special investigation as duplex for the venous system in patients were performed thigh liposuction, preoperative measurements as measuring the total body fat by InBody (570 body composition analyzer device), (It is a non-invasive, easy to use, multi-frequency bioelectrical impedance completed In Body 570 Body Composition Analyzer (Made in Biospace). Body composition is obtained from the measures of resistance and reactance when an electrical current travels throughout the body. The InBody was developed by Dr. Kichul Cha in 1996, InBody 570 is a multifrequency analyzer and divides the body into five components: Two arms, two legs, and a trunk. The electrodes are situated beneath the subject's feet on the platform and on the palms and thumbs attached to handles on the device. Age, height, and gender are manually entered after weight is determined by a scale positioned within device. Total body water, segmental impedance, extracellular and intracellular water were all measured with the subject's bare skin in contact with the 74 electrodes. Body mass and impedance are automatically assessed through the manufacturer software. Equations supplied in the manufacturer's proprietary software calculated fat free mass and body fat percentage. Prior to each assessment the electrodes were thoroughly cleansed with InBody provided tissues. After the device obtained subject weight the client was then instructed from the software to stand fully erect, arms extended and not touching side of the body, and to refrain from moving or talking until the assessment was completed). All patients were exposed for large volume liposuction signed an informed consent before the operation. Four photographic views were taken: A frontal view, two lateral views (on both sides) and A posterior view. Before the operation, preparing packed red blood cells and fresh frozen plasma to be available when needed in and after the operation. Surgical Technique: All cases were done in a wellequipped operation room with a good lightening and anti-septic measures. Accurate Preoperative markings are essential in standing position, regionsto be suctioned are delineated by a fiber tip marking pen. Areas that to be avoided or areas need for fat grafting also are independent lyoutlined by another marking pen. Port sites in every are a were also identified to permit cross-tunneling suction to decrease abnormalities in surface.

In the operating room, in a sterile operating table. We prepare the patient in a circumferential manner in the middle and lower limb so that, these areas can be suctioned without repositioning. Then the patient's skin is sterilized. After finishing the skin sterilization, the patient is sedated or given territorial and regional anesthesia as needed. 
All zones to be suctioned are injected with large volume of the tumescent infiltration fluid till the turgor of the tissue is to some extent equal in both sides. Effective vasoconstriction is reached in about 10 minutes, but it is moreeffective after about 20 minutes. The tumescent fluid was used: Ringer lactate, $0.1 \%$ lidocaine $(0.075$ to $1000 \mathrm{mg} / \mathrm{L}$ ringer lactate), Injectable adrenaline (was derived by careful observation of cutaneous blanching and pulse rate as a dose 0.65 to $1.0 \mathrm{mg} / \mathrm{L}$ ).

In the postoperative period patients wore pressure garments up to 3 months to facilitate better skin retraction, also the patients were on diet regimen and sport program till 6 months with monthly measuring the body weight and BMI.

\section{Statistical analysis:}

The data and information gathered were organized, tabulated \& analyzed by SPSS (statistical package for the social science software) statistical package version 22 on IBM viable computer.

Student t-test: Quantitative information were communicated as mean \& standard deviation $(\mathrm{X} \pm \mathrm{SD})$ and then examined and analyzed by applying student $t$-test for correlationof two groups of ordinarily dispersed variables and Mann-Whitney test: (a test of significant used for comparison between two groups having quantitative variables with independent non-parametric data) for nontypically distributed ones.

ANOVA test: It was done to compare three factors; one qualitative variable and the other two are quantitative factors of regularly conveyed factors and $p$-value $<0.05$ was viewed as significant asidentify mean and standard deviation so post hoc tests done to recognize the connection between factors within groups.

Chi square test: Qualitative information were communicated as number and percentage (No \& $\%)$ and analyzed by applying chi-square test. Whatever the expected values in one or more of the cells in a $2 \times 2$ tables was less than 5 , fisher definite test was utilized all things considered.

Person correlation test: It was done to examine relationship between one qualitative variable and one quantitative variable or two quantitative variables of not regularly appropriated information and $p$-value less than 0.05 was considered significant.

Every one of these tests, were utilized as trial of significance at $p<0.05$.

\section{RESULTS}

In our study 31 patients underwent large volume liposuction, 8 patients were males $(25.8 \%)$, and 23 patients were females (74.2\%). The mean age of patients was $36.87 \pm 5.86$ (Table 1).

The preoperative measurements as measuring the total body fat by InBody, as all patients who were divided by BMI were obese patients all high total body fat. On the other hand Postoperatively after 3 months, we found that of the 21 patients $(67.7 \%)$ in obese patients the total body fat still high, while 10 patients $(32.3 \%)$ there was a decrease the total body fat and change from obese to overweight patients, After 6 month only 9 patients (29\%) still had high total body fat in overweight patients, while 14 patients $(45.2 \%)$ there was a decrease the total body fat and turn to overweight patient and 8 patients $(25.8 \%)$ turned to normal total body fat, So There were statistically significant difference between preoperative measurements of total body fat (3 months, 6 months) postoperatively $(p<0.01)$.

In measurement of visceral fat by InBody device preoperatively, 30 patients were high $(96.8 \%)$ and only one patient was normal $(3.2 \%)$, then after 3 month postoperative 20 patients were still high $(64.5 \%)$ and 11 patients turned to normal $(35.5 \%)$ while after 6 months only 10 patients were still high $(32.3 \%)$ and 21 patients $(67.7 \%)$ turned to be normal, Regarding to in body measurements of visceral fat, there were statistically significant difference between the preoperative measurements of visceral fat and postoperative measurements (after 3 months and 6 months) $(p<0.01)$.

Regarding to the patient's investigations: Preoperative abdominal ultrasound was done to detect fatty liver; preoperatively fatty liver was found in 29 patients $(93.6 \%)$ and 2 patients were normal (6.4\%). Postoperatively after 3 months 22 patients still had fatty liver $(71.0 \%)$ and 9 patients turned normal $(29.0 \%)$ while after 6 months postoperatively only 11 patients still had fatty liver $(35.5 \%)$ and 20 patients turned normal $(64.5 \%)$. There was statistically significant difference between the presence of preoperative fatty liver and postoperative (three and six months) $(p<0.01)$ (Table 2).

There were statistically significant differences as regard to weight of patients, body mass index (BMI), total body fat and visceral fat according to the InBody device $(p<0.01)$.

Preoperatively, the mean weight of patients was (91 \pm 13.20$)$, while, postoperatively after 3 months 
the mean weight was $(85 \pm 12)$, and after 6 months the mean was $(80.67 \pm 12.37)$.

In BMI, preoperatively the mean of BMI was (32.5 \pm 2.6$)$, while postoperative after 3 months the mean was $(30.45 \pm 2.74)$ and after 6 months the mean was $(28.83 \pm 2.87)$.

In measurements of total body fat, preoperatively, the mean was $(40.06 \pm 4.47)$, while postoperatively after 3 months the mean was $(35.1 \pm 5.2)$ and after 6 months the mean was $(29.19 \pm 5.21)$.

In measurements of visceral fat, preoperatively, the mean was (12.6 \pm 2.44$)$, while postoperative, after 3 months the mean was $(10.58 \pm 2.1)$, and after 6 months the mean was $(8.9 \pm 1.5)$ Table (3).

There was no statistically significant difference as regard the relation between the amount of liposuction and the average weight loss at 6 months after operation.

As in conventional liposuction $(4.000 \mathrm{ml}$ to $<5.000 \mathrm{ml}$ ), only one patient with average weight loss after 6 months was $10 \mathrm{~kg}$, while in amount of lipoaspirate (5.000 to 7.999) in 18 patients, the average of their weight loss after 6 months was $(8.78 \pm 4.2)$.

In amount of liposuction $(8.000 \mathrm{ml}$ to $11.999 \mathrm{ml})$ in 10 patients, the average of their weight loss after 6 months was $(13.4 \pm 4.9)$.

While, in amount of liposuction $>12.000 \mathrm{ml}$ in 2 patients the average weight loss after 6 months

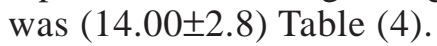

There was a statistically difference as regard to the relation to the amount of the aspirate of liposuction and the satisfaction of patients (as the shape of their body) $(p<0.01)$.
There were no significant differences between preoperative and postoperative (after 3 and after 6 months) to the mean of the circumference of arm and thigh $(p>0.05)$. On the other hand there were statistically difference as regard to the mean circumference of the abdomen $(p<0.01)$ as the mean circumference preoperatively was $(99.54 \pm 14.22)$, while 3 months postoperatively the mean circumference was $(92.29 \pm 13.35)$ and 6 months postoperatively the mean circumference was $(88.677 \pm$ 12.92).

Also there were statistically difference to the mean of the circumference of the gluteal region as preoperatively was (112.41 \pm 15.83$)$, while 3 months postoperatively the mean circumference was (104.22 \pm 15.7$)$ and 6 months postoperatively the mean circumference was $(99.61 \pm 15.41)$. Table (5).

As with increase the amount of aspirate of liposuction as the mean $(7.78 \pm 2.2), 27$ patients $(87.1 \%)$ were satisfied (the patients were satisfied about their shape and body contour), while, with decrease amount of aspirate of liposuction as the mean $(6.25 \pm 0.96)$, 4 patients $(12.9 \%)$ were unsatisfied (the patients were unsatisfied about their shape and body contour) as increasing their expectation about the contour of their body Table (6).

Table (1): Socio demographic of patients.

\begin{tabular}{cll}
\hline Variables & No. & $\%$ \\
\hline Age: & \multicolumn{3}{c}{$36.87 \pm 5.86$} \\
Mean \pm SD & \multicolumn{2}{c}{38} \\
Median & \multicolumn{2}{c}{$28-46$} \\
Range & 2 & 6.5 \\
$20-29$ & 23 & 74.2 \\
$30-39$ & 6 & 19.4 \\
$40-50$ & & \\
Sex: & 8 & 25.8 \\
Male & 23 & 74.2 \\
Female & & \\
\hline
\end{tabular}

Table (2): Preoperative and Postoperative (after 3 months and 6 months) measurements and investigation.

\begin{tabular}{|c|c|c|c|c|c|c|c|c|}
\hline \multirow{2}{*}{ Variables } & \multicolumn{2}{|c|}{ Before operation } & \multicolumn{2}{|c|}{ After 3 months } & \multicolumn{2}{|c|}{ After 6 months } & \multirow{2}{*}{$x^{2}$} & \multirow{2}{*}{$p$-value } \\
\hline & No. & $\%$ & No. & $\%$ & No. & $\%$ & & \\
\hline \multicolumn{9}{|l|}{ Body fat: } \\
\hline 18-24.9 (Normal) & 0 & 0 & 0 & 0 & 8 & 25.8 & \multirow[t]{3}{*}{40.93} & \multirow[t]{3}{*}{$0.001 * *$} \\
\hline 25-29.9 (Over weight) & 0 & 0 & 10 & 32.3 & 14 & 45.2 & & \\
\hline$>30$ (Obese) & 31 & 100 & 21 & 67.7 & 9 & 29 & & \\
\hline \multicolumn{9}{|l|}{ Visceral fat: } \\
\hline High & 30 & 96.8 & 20 & 64.5 & 10 & 32.3 & \multirow[t]{2}{*}{30.69} & \multirow[t]{2}{*}{$0.001 * *$} \\
\hline Normal & 1 & 3.2 & 11 & 35.5 & 21 & 67.7 & & \\
\hline \multicolumn{9}{|l|}{ (Abdominal U S Fatty liver): } \\
\hline Fatty liver & 29 & 93.6 & 22 & 71.0 & 11 & 35.5 & \multirow[t]{2}{*}{30.9} & \multirow[t]{2}{*}{$0.001 * *$} \\
\hline Normal & 2 & 6.4 & 9 & 29.0 & 20 & 64.5 & & \\
\hline
\end{tabular}

$* p<0.05=$ Significant. 
Table (3): Preoperative and Postoperative (3 months and 6 months) measurements.

\begin{tabular}{llllll}
\hline Variables & Before & After $3 \mathrm{~m}$ & After $6 \mathrm{~m}$ & F-test & $p$-value \\
\hline Weight & $91 \pm 13.20$ & $85 \pm 12$ & $80.67 \pm 12.37$ & 5.565 & $0.005^{* *}$ \\
BMI & $32.5 \pm 2.6$ & $30.45 \pm 2.74$ & $28.83 \pm 2.87$ & 14.589 & $0.001^{* *}$ \\
Total Body fat & $40.06 \pm 4.47$ & $35.1 \pm 5.2$ & $29.19 \pm 5.21$ & 37.03 & $0.001^{* *}$ \\
Visceral fat & $12.6 \pm 2.44$ & $10.58 \pm 2.1$ & $8.9 \pm 1.5$ & 25.3 & $0.001^{* *}$ \\
\hline
\end{tabular}

$* p<0.05=$ Significant.

Table (4): Preoperative and Postoperative (3 months and 6 months) means of the circumference of the arm, thigh, abdomen and buttock.

\begin{tabular}{llllll}
\hline Circumference of & \multicolumn{1}{c}{ Before } & After $3 \mathrm{~m}$ & After $6 \mathrm{~m}$ & F-test & $p$-value \\
\hline Arm & $36.16 \pm 8.69$ & $33.45 \pm 7.6$ & $32 \pm 7.31$ & 1.469 & 0.236 \\
Thigh & $75.2 \pm 10.61$ & $69.74 \pm 11.2$ & $66.35 \pm 10.28$ & 2.726 & 0.071 \\
Abdomen & $99.54 \pm 14.22$ & $92.29 \pm 13.35$ & $88.677 \pm 12.92$ & 5.683 & $0.005^{* *}$ \\
Buttock & $112.41 \pm 15.83$ & $104.22 \pm 15.7$ & $99.61 \pm 15.41$ & 4.318 & $0.016^{*}$ \\
\hline
\end{tabular}

$(p<0.05)$ Significant.

Table (5): Correlation between amount of Liposuction and Average of weight loss after 6 months.

\begin{tabular}{|c|c|c|c|c|c|c|c|}
\hline \multirow{3}{*}{ Variables } & \multicolumn{5}{|c|}{ Liposuction volume (in ml) } & \multirow{3}{*}{\multicolumn{2}{|c|}{$\begin{array}{cc}\text { F- } & p- \\
\text { test } & \text { value }\end{array}$}} \\
\hline & \multirow{2}{*}{$\begin{array}{c}\begin{array}{c}\text { Conventional } \\
\text { liposuction }\end{array} \\
4.000 \text { to }<5.000\end{array}$} & \multicolumn{3}{|c|}{$\begin{array}{c}\text { Mega } \\
\text { liposuction }\end{array}$} & \multirow{2}{*}{$\begin{array}{l}\text { Total } \\
\text { patient no }\end{array}$} & & \\
\hline & & $5.000-7.999$ & 8.000-11.999 & $\geq 12.000$ & & & \\
\hline No. of patients & 1 & 18 & 10 & 2 & 31 & 276 & 0062 \\
\hline $\begin{array}{l}\text { Average of weight } \\
\text { loss at } 6 \text { months } / \mathrm{Kg}\end{array}$ & $\begin{array}{l}10 \pm 0.0 \\
(10-10)\end{array}$ & $\begin{array}{c}8.78 \pm 4.2 \\
(3-23)\end{array}$ & $\begin{array}{c}13.4 \pm 4.9 \\
(9-20)\end{array}$ & $\begin{array}{c}14.00 \pm 2.8 \\
(12-16)\end{array}$ & $\begin{array}{l}10.19 \pm 4.75 \\
\quad(3-23)\end{array}$ & 2.10 & \\
\hline
\end{tabular}

${ }^{*} p<0.05=$ Significant.

Table (6): Relation between the satisfaction of patient and the amount of large volume liposuction.

\begin{tabular}{lcclcl}
\hline Patient satisfaction & No. & $\%$ & Liposuction & $X^{2}$ & $p$-value \\
\hline Satisfied & 27 & 87.1 & $7.78 \pm 2.2$ & & \\
Unsatisfied & 4 & 12.9 & $6.25 \pm 0.96$ & 8.66 & $0.02 *$ \\
\hline
\end{tabular}

${ }^{*} p<0.05=$ Significant.

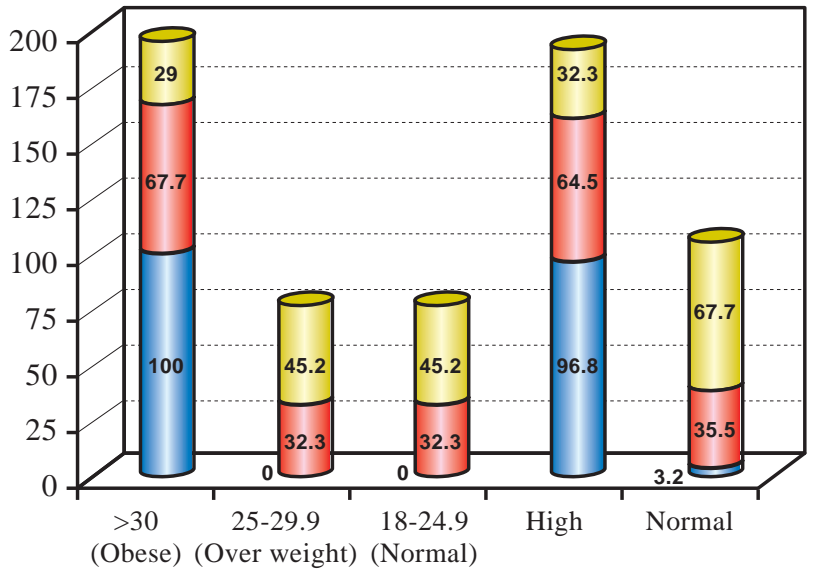

Body fat

Visceral fat

Before operation $\square$ After $3 \mathrm{~m} \quad \square$ After $6 \mathrm{~m}$

Fig. (1): Preoperative and postoperative (after 3 months and after 6 months) measurements as InBody for measurements of the total body fat and the visceral fat.

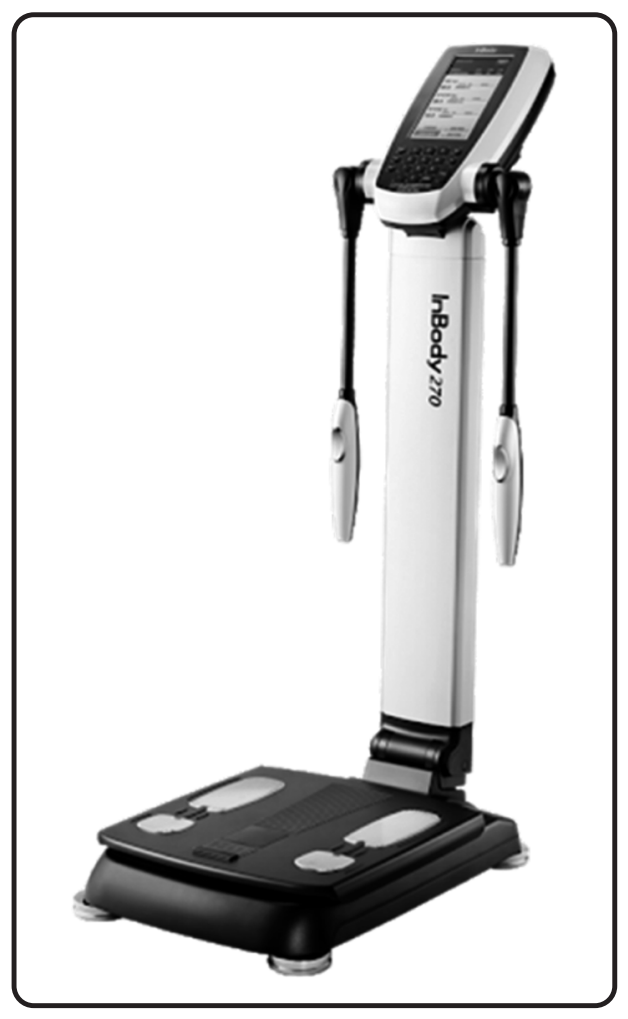

Fig. (2): Body fat analyzer machine: InBody India (Made in Biospace). 


\section{DISCUSSION}

Liposuction is a very common cosmetic operation as it is safe, simple and effective way in body contouring. The progress of the amount of aspirate of liposuction as small region operation to the total body contouring. So, the large volume liposuction physiology on patients exposes them to prolonged operation. Advance in techniques enable surgeon to perform large volume liposuction more securely with less blood loss. The significant aspiration of subcutaneous fat by large volume liposuction evidently improves the body arrangement of fat, rapidly decreasing the amount of subcutaneous fat. It also has a good effect on body weight and bodymass index (BMI) also on body fat [9].

In our study 31 patients underwent large volume liposuction, (8) eight patients were males (25.8\%), (23) twenty-three patients were females $(74.2 \%)$. The mean age of patients was $36.87 \pm 5.86$. Han et al., [10]: With a total of 83 patients found that the mean of age (31 \pm 9.1$)$, and Habibet al., [11] found the mean of age (31.27 \pm 5.69$)$.

In our study the preoperative measurements as InBody device to measure the total body fat among the all patients as all patients which divided by BMI overweight patients. On the other hand 3 months postoperatively, we found that the 21 patients $(67.7 \%)$ in obese patients the total body fat was still high, while in 10 patients $(32.3 \%)$ there was a decrease of the total body fat and turn from obese to overweight patients, As regard after 6 month only 9 patients (29\%) had still high total body fat in overweight patients, while 14 patients $(45.2 \%)$ there was a decrease of the total body fat and turn to overweight patient and 8 patients $(25.8 \%)$ turned to normal total body fat. So,there were statistically significant difference between preoperative measurements of total body fat and (3 months, 6 months) postoperatively.

In measurement of visceral fat by InBody device preoperatively, 30 patients were high $(96.8 \%)$ and only one patient was normal (3.2\%), then after 3 month postoperative 20 patients were still high $(64.5 \%)$ and 11 patients turned to normal $(35.5 \%)$ while after 6 months only 10 patients were still high $(32.3 \%)$ and 21 patients $(67.7 \%)$ turned to normal, regarding the InBody measurements of visceral fat, there were statistically significant difference between the preoperative measurements of visceral fat and postoperative measurements (after 3 months and 6 months).

Preoperative abdominal ultrasound showed that fatty liver was found in 29 patients (93.6\%) preop- eratively and in 2 patients were normal (6.4\%). Postoperatively follow-up with abdominal ultrasound showed that after 3 months 22 patients still had fatty liver (71.0\%) and 9 patients turned normal $(29.0 \%)$ while after 6 months only 11 patients still had fatty liver $(35.5 \%)$ and 20 patients turned normal $(64.5 \%)$. There were statistically significant difference between the presence of preoperative fatty liver and postoperative (three and six months).

Dhamiet al., [12], in their study found that weight reduction at patients 6 months after surgery follow-up visit from 1 to $25 \mathrm{~kg}$ (average $9.5 \mathrm{~kg}$ ).

Geliebter et al., [13], demonstrated that body composition analysis at 10 weeks after liposuction caused a $(9.4 \pm 1.8)$ kgreduction in body fat $(16 \pm 2 \%)$ of total fat mass. While the visceral adipose tissuedid not change.

There were statistically significant differences as regard to weight of patients, body mass index (BMI), total body fat and visceral fat according to the In-body device $(p<0.01)$.

Preoperatively, the mean of weight of patients was $(91 \pm 13.20)$, while, postoperatively after 3 months the mean of weight was $(85 \pm 12)$, and after 6 months the mean was $(80.67 \pm 12.37)$.

In BMI, preoperatively the mean of BMI was (32.5 \pm 2.6 ), while postoperative after 3 months the mean was $(30.45 \pm 2.74)$ and after 6 months the mean was (28.83 \pm 2.87$)$. In measurements of total body fat, preoperatively, the mean was $(40.06 \pm$ 4.47), while postoperatively after 3 months the mean was $(35.1 \pm 5.2)$ and after 6 months the mean was (29.19 \pm 5.21$)$.In measurements of visceral fat, preoperatively, the mean was $(12.6 \pm 2.44)$, while postoperative, after 3 months the mean was (10.58 $2.1)$, and after 6 months the mean was $(8.9 \pm 1.5)$. In contrast with Saleh et al., [7], in the study of 60 patients weight and BMI significantly decreased preoperatively as the mean of the weight (91.3 \pm 17.6), while after 4 months postoperatively the mean of weight $(76.95 \pm 14.9)$ and BMI preoperatively the mean (34.95 \pm 5.9$)$ and 4 months postoperatively the mean of BMI (29.69 \pm 5.2$)$.

There was no statistically significant difference as regard to the relation between the amount of liposuction and the average of weight loss at 6 months after operation.

As in conventional liposuction $(4.000 \mathrm{ml}$ to $<5.000 \mathrm{ml}$ ) in one patient with average weight loss after 6 months was $10 \mathrm{~kg}$, while in amount of liposuction (5.000 to 7.999) in 18 patients, the average weight loss after 6 months was $(8.78 \pm 4.2)$. 
In amount of liposuction $(8.000 \mathrm{ml}$ to $11.999 \mathrm{ml})$ in 10 patients, the average weight loss after 6 months was (13.4 \pm 4.9$)$. While, in amount of liposuction $>12.000 \mathrm{ml}$ in 2 patients the average weight loss after 6 months was (14.00 \pm 2.8$)$.

As the effect of large volume liposuction in our study there were significant effect on the circumference of abdominal and gluteal region, with no significant effect on the circumference of thigh. Saleh et al., [7] in their study showed that significant effect in buttock and thigh measurements preoperatively and 4 months after large volume liposuction. Geliebter et al., [13], found that abdominal circumference decreased overtime, in periods from October 2015 to May 2017 with total of 83 patients.

There was a statistical difference as regard to the relation to the amount of the aspirate of liposuction and the satisfaction of patients $(p<0.01)$. As with increase the amount of aspirate of liposuction as the mean $(7.78 \pm 2.2), 27$ patients $(87.1 \%)$ were satisfied, while with decrease amount of aspirate of liposuction as the mean $(6.25 \pm 0.96), 4$ patients $(12.9 \%)$ were unsatisfied. In contrast to Ahmad et al., [14], found that liposuction volume between 5 and 25 liters with mean of 15.5 liters were suctioned. Weight reduction at the patient's follow-up to 6 months post-surgery varied from 1 to $25 \mathrm{~kg}$ with average of $9.5 \mathrm{~kg}$ ( $4 \%$ to $10 \%$ ) of preoperative body weight.

\section{Conclusion:}

This work was carried to study the effect of large volume liposuction on body composition. We found that the large volume liposuction in our patients significantly reduce the weight, BMI, total body fat, visceral fat, circumference of both abdomen and buttock.

No Funds.

No Conflict of Interest.

\section{REFERENCES}

1- Gabriel A. and Gingrass M.K.: Large Volume Liposuction Safety and Indications. CME \& Education, Medscape, 2014.
2- Perez R.A.: Liposuction and diabetes type 2 development risk reduction in the obese patient. Medical hypotheses, Jan. 1; 68 (2): 393-6, 2007.

3- Evstatiev D. and Bŏchev B.: Liposuction in outpatient/oneday surgery. Khirurgiia, Jan. 1; 60 (6): 13-5, 2004.

4- Dhami L.D. and Agarwal M.: Safe total corporal contouring with large-volume liposuction for the obese patient. Aesthetic Plastic Surgery, Oct. 1; 30 (5): 574-88, 2006.

5- Gingrass M.K.: Liposuction. Grabb and smith's plastic surgery. $6^{\text {th }}$ ed. Philadelphia: Lippincott Williams \& Wilkins, 533-41, 2007.

6- Sailon A.M., Wasserburg J.R., Kling R.R., Pasick C.M. and Taub P.J.: Influence of large-volume liposuction on metabolic and cardiovascular health: A systematic review. Annals of Plastic Surgery, Dec. 1; 79 (6): 623-30, 2017.

7- Saleh Y., El-Oteify M., Tohamy A. and Abd-Elsayed A.A.: Safety and benefits of large-volume liposuction: A single center experience. International Archives of Medicine, Dec. 1; 2 (1): 4, 2009.

8- Greville W.L.: Proposed Safety Guidelines for the Maximum Volume Fat Removal by Tumescent Liposuction. InLiposuction (pp. 30-34). Springer, Berlin, Heidelberg, 2006.

9- Shim Y.H. and Zhang R.H.: Literature review to optimize the autologous fat transplantation procedure and recent technologies to improve graft viability and overall outcome: A systematic and retrospective analytic approach. Aesthetic Plastic Surgery, Aug. 1; 41 (4): 815-31, 2017.

10- Han F., Zhang S., Hou N., Wang D. and Sun X.: Irisin improves endothelial function in obese mice through the AMPK-eNOS pathway. American Journal of PhysiologyHeart and Circulatory Physiology, Nov. 309 (9): H15018, 2015.

11- Habib H., Abd Alazeem S. and Abd Alazeem N.: Fasting Insulin Level Changes after Large Volume Liposuction. The Egyptian Journal of Hospital Medicine, Oct. 1; 73 (3): 6243-51, 2018.

12- Dhami L.D.: Liposuction. Indian journal of plastic surgery: Official publication of the Association of Plastic Surgeons of India, Oct. 41 (Suppl): S27, 2008.

13- Geliebter A., Krawitz E., Ungredda T., Peresechenski E. and Giese S.Y.: Physiological and psychological changes following liposuction of large volumes of fat in overweight and obese women. Journal of Diabetes and Obesity, 2 (4): $1,2015$.

14- Ahmad J., Eaves III F.F., Rohrich R.J. and Kenkel J.M.: The American Society for Aesthetic Plastic Surgery (ASAPS) survey: Current trends in liposuction. Aesthetic Surgery Journal, Feb. 1; 31 (2): 214-24, 2011. 